\title{
The Association of Workplace Health Education on Smoking- Related Behaviour and Unequal Gains by Job Position in China: ABWMC Programme Findings
}

\author{
Haoxiang Lin \\ Peking University Health Science Centre \\ Meijun Chen \\ Peking University Health Science Centre \\ Yunting Zheng \\ Peking University Health Science Centre \\ Qingping Yun \\ Peking University Health Science Centre
}

Chun Chang ( $\nabla$ whostopsmoking@163.com )

Peking University Health Science Centre https://orcid.org/0000-0003-3203-8778

\section{Research Article}

Keywords: Smoke-free, Workplace, Health education

Posted Date: April 8th, 2021

DOl: https://doi.org/10.21203/rs.3.rs-384059/v1

License: (c) (i) This work is licensed under a Creative Commons Attribution 4.0 International License. Read Full License 


\section{Abstract}

Background

Although the Chinese government has introduced a series of regulations to promote tobacco-related health education in workplaces, the implementation has been far from satisfactory. The aim of the present study was to explore the association of company level tobacco-related health education and employee's smoking behavior.

Methods

Data from the 2018 Asia Best Workplace Mainland China programme were employed to address these aims. This was a crosssectional study that included 14195 employees from 79 companies in mainland China. Spearman correlation tests were used to examine unadjusted correlation between the study variables, and binary logistic regression was used for multivariable analysis. The dependent variables included the smoking-related variables or health information-seeking behaviour. The explanatory variable is the company level tobacco-related health education.

Results

Tobacco-related health education was associated with better smoking harm awareness, lower second-hand smoke exposure, better perceived workplace environment and positive health information-seeking behaviour. Job position interacted with health education, suggesting that positive association of health education were smaller for general employees than employees who held an administrative position.

Conclusions

We conclude that workplace tobacco-related health education was not only associated with tobacco control effects but also had spillover effects, which were significant for higher-ranking employees. Policy makers should recognize and reduce the potential health disparities.

\section{Introduction}

Smoking is one of the main risk factors driving the growing epidemic of noncommunicable diseases worldwide. Tobacco is on track to claim 200 million lives in China this century, predominantly among the poorest and most vulnerable people [1-2]. Although the rate of second-hand smoke (SHS) exposure has gradually decreased in China, workplace SHS exposures remain pervasive (i.e., $54.3 \%$ in 2015 to $50.9 \%$ in 2018) [3-4]. Company level tobacco-related health education for employees has contributed to effective tobacco control or SHS exposure reduction strategies [5-6].

Since the 1980s, the Chinese government has introduced a series of regulations to reduce SHS in workplaces, including smoking bans in public places and support for companies to conduct health education to employees. However, the implementation has been far from satisfactory[5]. Companies may be reluctant to provide health education due to a lack of time and knowledge. There is only a limited number of companies that have a smoke-free policy and that provide tobacco-related health education, resulting in few studies evaluating workplace health education and its impact on employee's smoking behaviour.

Prior to implementing potential robust measures to promote smoking-related health education in workplaces, it may be beneficial for policy makers to have a clear understanding of the impact of such activities in Chinese companies. For example, the most common outcomes assessed following health education is knowledge increase and SHS exposure reduction. However, little is known about how such activities influence employees, including their perceived workplace environment and regular health information-seeking behaviour.

Another relevant problem is unequal gain from tobacco health education. In western countries, researchers have found that people with different socio-economic status (SES) but equal health resources have unequal gains [7-8]. For example, one study has reported that African Americans do not gain as much self-rated health as Caucasians with the same resources [9]. Assari

Page 2/14 
and Bazargan found that the protective effects of educational attainment for reducing SHS exposure at work are systemically less for Hispanics than Whites [10]. Some scholars believe that the impact of resources on health outcomes are conditional to factors, such as SES, poverty and residential segregation [11-12].

According to The Minorities' Diminished Returns theory, at least some of the health disparities are due to "less than expected" protective effects, suggesting that population level health disparities are not all due to resource but also due to differential health gain [9-10]. One recent Chinese study has found that higher SES families have better self-reported health and fewer activities of daily living limitations with the same society resource [13]. However, there are no previously reported studies on health gain difference for tobacco-related health education. Because of the sustained increase in health status disparities in China in the past half century, the difference of population level spillover effects from health education have become increasingly important both for scholars and policy makers [14]. In this paper, we refer to indirect association of tobacco-related health education beyond reducing SHS exposure and enhancing smoking harm awareness as spillover effects, including the influence on perceived workplace environment and health information-seeking behaviour.

The aim of the present study was to explore the association of company level tobacco-related health education and employee's smoking behavior. Specifically, we have the following hypotheses: (1) with company level health education, employees will not only indicate a higher smoking harm awareness and a lower SHS exposure but also show spillover effects about their perceived working environment and health behaviour; and (2) several positive associations of health education are fewer for lower ranking employees than higher ranking employees.

\section{Methods}

\section{Design and data}

Data from the 2018 Asia Best Workplace Mainland China (ABWMC) programme were employed to address these aims. ABWMC is an academic/company partnership programme that aims to support companies in building a healthy workplace. The ABWMC programme was designed by Peking University and organized by the American International Assurance Co. All companies may voluntarily join the programme and are free to withdraw. The inclusion criteria were as follows: (1) registered legal companies in China; (2) agreement to participate in the programme; and (3) at least 100 workers who are full-time employees. We used information from baseline employee questionnaires. The inclusion criteria for participating employees were as follows: (1) aged 18 years old or above; (2) full-time employees; and (3) agreement to participate in the programme.

The human resource departments of each company delivered the questionnaires to all employees. When first opening the link, content related to informed consent was shown, and employees were able to choose whether to complete the questionnaire or quit. If the employees submitted the questionnaire through the link, we considered that they agreed to participate. The self-check function of the online survey system automatically identified missing data, logical errors and illegal characters.

\section{Measurements}

\section{Smoking harm awareness}

Smoking harm awareness was measured by the following question: 'Do you think smoking can cause any of the following diseases? A: stroke, B: heart disease, C: lung cancer, D: cardiovascular disease, E: chronic obstructive pulmonary disease, F: asthma or G: I don't know.' Only the participants who chose all answers from A to F were classified as having smoking harm awareness.

\section{SHS exposure}

In the survey, the participants were asked the following question: 'How many days a week do you usually suffer from SHS exposure at workplace for more than 15 minutes? A: almost every day, B: 4-6 days, C:1-3 days or D: never'. Only the participants who chose D were classified as having no SHS exposure. 


\section{Tobacco-related health education}

We defined tobacco-related health education as follows: (1) organized by company level; (2) all employees have opportunities to join; and (3) the contents should be related to tobacco control or smoking cessation. This definition was explained to the respondents when conducted the survey.

Such activities were measured by two questions. The participants were asked the following questions: 'Does your company provide you with tobacco related health education? A: Yes or B: No'. Respondents who answered 'Yes' were then asked 'Have you ever participated such activities? A: Yes or B: No'.

We further classify all respondents into three categories: have tobacco-related health education and also attend such activities (both of the questions answered 'Yes'=2); have tobacco-related health education but not attend such activities (first question answered 'Yes', second answered ' $N o$ ' $=1$ ); without tobacco-related health education (Otherwise $=0$ )

\section{Perceived workplace environment}

There were two variables for this characteristic. The first variable was for the employees to believe that they work in a healthy environment, and the second variable was for the employees to believe that the company policy protects health. For the first variable, participants were asked the following question: 'Do you think your working environment is healthy? A: I totally agree, B: I Agree, C: Just ok, D: I do not agree, or E: I totally disagree. Only the participants who chose A and B were classified as believing that they work in a healthy environment.

For the second variable, participants were asked the following question: 'Do you think your company's policy can protect your health? A: I totally agree, B: I Agree, C: Just ok, D: I do not agree, or E: I totally disagree. Only the participants who chose A and B were classified as believing that their workplace policy protects the health of employees.

All the participants need answer these questions.

\section{Health information-seeking behaviour}

In the survey, the participants were asked the following question: 'How often do you search for health knowledge? A: Always, B: Very often, C: Sometimes, D: Occasionally, or E: Never. Only the participants who chose A and B were classified as having such behaviour regularly.

\section{Other covariates}

We controlled for several variables of individual characteristics, such as gender, age, marital status, education, ethnicity and job position. For job position, we further classified all employees into two categories as follows: administrative employees (participants with administrative rank) and non-administrative employees (participants without administrative rank).

\section{Data analytical plan}

Our data have a hierarchical structure, therefore we firstly try to use multilevel analyses by setting individual-level and companylevel factors. This type of analysis will take into account the fact that workers' responses are correlated within companies. We run four standardized models (Null model, Random coefficients regression model, Intercepts as model; Slopes as outcomes model). However, when we finished the Null model, we find intraclass correlation coefficient (ICC) is too low (lower than 0.059), is 0.051 , indicating that only about $5.1 \%$ of the total variation on SHS exposure was attributable to differences between companies/clusters [15]. In other word, we can use usual method to perform analyses. Therefore, we use logistic regression for our statistics.

Our data analysis was conducted in three steps. First, we examined the distribution of the categorical and continuous variables. Second, Spearman correlation tests were used to examine unadjusted correlation between study variables. Third, we performed binary logistic regression for multivariable analysis. 
The dependent variables included the smoking-related variables (smoking harm awareness and SHS exposure), working environment variable (perceived workplace environment) or health information-seeking behaviour. The explanatory variable indicated if the company provided tobacco-related health education (yes $=1$ or otherwise $=0$ ).

To examine whether there was an interaction effect between job position and health education, we further conducted regression analysis using two models. Model 1 only entered the main effects of health education, job position and covariates. Model 2 also added an interaction term between job position and health education.

We used SPSS 24.0囚SPSS Inc, Beijing, China囚statistical software to conduct all analyses.

\section{Ethics}

All participants were informed that the research team would analyze the data anonymously. This study was approved by the Peking University (ethical approval number: IRB00001052-18055).

\section{Results}

\section{Descriptive statistics}

The total number of participants was 14195 employees from 79 companies in mainland China. The companies included $51.9 \%$ private companies, $32.9 \%$ foreign companies, $7.6 \%$ state-owned companies, $6.3 \%$ joint ventures, and $1.3 \%$ other companies. The respondents included 5802 (40.9\%) employees who reported working in companies that have tobacco-related health education and 8393 (59.1\%) employees who reported working in companies without such activities. Among all the respondents who reported that their companies have health education, $2317(39.9 \%)$ reported they did not participate in such activities. Table 1 shows the descriptive statistics of the overall sample.

Figure 1 shows the relationship between tobacco-related health education and other key characteristics. Employees in companies with health education reported lower proportion of SHS exposure, higher proportion of smoking harm awareness, higher proportion of perceived safe workplace environment and more positive health information-seeking behaviour.

\section{Bivariate analysis}

Table 2 shows bivariate correlations between the study variables. Health education was positively correlated with smoking harm awareness, perceived safe workplace environment and health information-seeking behaviour. Moreover, health education was inversely correlated with SHS exposure. Education attainment was also associated with the positive effects, except SHS exposure.

\section{Multivariable models (outcome: smoking harm awareness and SHS exposure)}

Table 3 presents the summary of the results for both logistic regression models with health education as the independent variable as well as SHS exposure and smoking harm awareness as the dependent variables. Based on Model 1, health education was associated with better smoking harm awareness and lower odds of workplace SHS exposure. No significant interactions were identified between job position and health education for these tobacco control effects.

\section{Multivariable models (outcome: perceived workplace environment and health information-seeking behaviour)}

Table 4 presents the summary of the results of both logistic regression models with health education as the independent variable as well as perceived workplace environment and health information-seeking behaviour as the dependent variables. Based on Model 1, heath education was associated with higher odds of perceived healthy workplace environment and health information-seeking behaviours. Model 2 showed significant interactions between job position and health education with spillover effects, suggesting that company level tobacco-related health education has larger positive associations on perceived workplace environment and health information-seeking behaviours for administrative employees than general employees, which was evidenced by the odds ratio being greater than 1 for the interaction terms. 
In addition, compare with the respondents who not attend of company level tobacco related health education, both model show that attend respondents have more significate positive influence on all the outcome variables.

\section{Discussion}

The present study evaluated the possible influence of company level tobacco-related health education, and it showed that tobacco-related health education is not only associated with better tobacco control effects but is also related to some spillover effects. Consistent with predictions, health education was associated with better smoking harm awareness, lower SHS exposure, better perceived workplace environment and positive health information-seeking behaviour. In addition, the interaction between job position and health education moderated the spillover effects.

Change in knowledge is often targeted because it is recognized as fundamental to change health behaviour in various behavioural theories [16]. The demonstrated associations are particularly notable given that the awareness of tobacco harm is a commonly cited barrier to conduct more active tobacco control measures. By addressing this barrier through health education, the implementation of workplace health promotion measures is more practicable. However, the positive association with awareness of tobacco harm suggests that the delivered education session may be an effective method to increase the understanding of the company level smoke-free workplace policy and encourage compliance with the policy.

Although several studies have found that participation in workplace tobacco-related health education has led to improving smoking harm awareness and quitting intention[17], the possible association in the present study were much more comprehensive, resulting in positive association of health behaviour and health attitude. Therefore, as this study indicated, implementation of a workplace health education may be an opportunity to improve the health of employees via multiple levels.

Although health education has overall positive association with employee perception of work environment and health information-seeking behaviour, such associations should not be considered equal between common employees and administrative employees. Some recent studies have found similar patterns for the associations between a wide range of SES indicators and health outcomes [18-20] In the United States, economic resources and psychological assets systemically result in a smaller health gain for some populations, suggesting that the mechanism generating health disparities is more than differential exposures to resources. ${ }^{8}$

Our findings have practical implications. The present study highlights the importance of offering health education from a company level with the optimal method being to incorporate short time health education into routine activities. The lack of health education may translate into a 'missed opportunity' to promote population health in a cost-effective way. The first step towards the universal adoption of health education provision in workplaces is to educate policy makers and leaders of workplaces. Therefore, the survey report will be disseminated to the participating companies and government agencies, which will aim to encourage those struggling to catch up and provide accessible options and implement other key health education measures.

Moreover, given the possible existing unequal gain of equal health education, policies that merely focus on the equal distribution of resources and ignore the differential distribution of barriers across groups could be a potential problem. The spillover effects associated with tobacco-related health education were not equal. Further studies should explore other health indicators related to this topic because the ultimate objective of such activities is to promote health and reduce health disparities at the same time. Thus, a related health program should avoid the unintended effect of exacerbating the existing health inequities rather than reducing them.

It is worth noting, we found that the outcome variables in most models are significantly higher or lower not only among those participants who reported attending the health education classes but also among those who only reported that this education is adopted in the company. Therefore, it is possible health education is not the main factors caused the observed effects. For example, if the non-controlled factor was 'willingness to show that the company is a good one', people with higher values of this factor would more likely report that work environment is healthy and that they are interested in health-related information. Future research would benefit from using other methods that could better identify such hidden factors. 
The present study had several limitations. First, we used only cross-sectional data for estimation. what we have revealed were pure associations, not the direct effects of health education. After the ABWMC programme conducts additional follow-up surveys, it will be possible to perform a longitudinal study to obtain more convincing findings. Second, the current study was limited to interested companies, thereby potentially introducing selection bias, and we did not recruit any participants from other areas, such as government employees. Third, our results were based on self-report information. It was not possible to objectively verify the survey answers, and some respondents may not have provided real information. Fourth, As the study was not an experimental one but a cross-sectional survey, it is possible that some other factors caused the observed effects.

\section{Conclusion}

Taken together, the results of this empirical analysis not only contribute to identifying the possible influence of workplace tobacco-related health education but also provide further evidence regarding the association of spillover effects with such activates and adds to earlier research. Further analyses suggested that job position is among the channels moderating such beneficial association. Policy makers should recognize and reduce the potential health disparities.

\section{Abbreviations}

SHS: second-hand smoke; SES: socio-economic status; ABWMC: Asia Best Workplace Mainland China;

ICC: intraclass correlation coefficient.

\section{Declarations}

\section{Acknowledgements}

N/A

\section{Author contributions}

Haoxiang Lin and Meijun Chen finished the first draft, should contributed equally to this study. Chun Chang managed all the research. All the other authors conduct the survey. All authors contributed to the subsequent revisions of the paper and have approved the final paper for submission.

\section{Funding}

This study was supported by AIA Company limited.

\section{Availability of data and materials}

The datasets generated and/or analysed during the current study are not publicly available due to ethical restrictions but are available from the corresponding author on reasonable request.

\section{Declarations}

\section{Ethics approval and consent to participate}

This study was approved by the Peking University (Ethical approval number: IRB00001052-18055). All the participants were informed consent.

\section{Consent for publication}

All authors consent to this manuscript's publication. 
The authors declare that they have no competing interests.

\section{References}

1. World Health Organization. The bill China cannot afford: health,economic and social costs of China's tobacco epidemic. Manila, Philippines: World Health Organization Regional Office for the Western Pacific; 2017. https://iris.wpro.who.int/handle/10665.1/13566.

2. Lin H, Xiao D, Liu Z, Shi Q, Hajek P, Wang C. National survey of smoking cessation provision in China. Tobacco Induced Diseases. 2019;17(April):25. doi:10.18332/tid/104726.

3. China Disease Control and Prevention Center. 2015 China Adult Tobacco Survey. Beijing: China CDC, 2016.

4. China Disease Control and Prevention Center. 2018 China Adult Tobacco Survey. Beijing: China CDC, 2019.

5. Gao JN, Zheng PP, Gao JL, chapman S, Fu H. Workplace smoking policies and their association with male employees smoking behaviours: a cross-sectional survey in one company in China. TOB CONTROL, 2011, 20(2):131-136.

6. Tabuchi T, Colwell B. Disparity and Trends in Secondhand Smoke Exposure among Japanese Employees, Particularly Smokers vs. Non-Smokers. PLoS One, 2016, 11 (4): e0152096.

7. Assari S. Health disparities due to diminished return among black Americans: Public policy solutions. Soclssues Policy Rev 2018;12:112-45.

8. Assari S. Unequal gain of equal resources across racial groups. Int J Health Policy Manag 2017;7:1-9.

9. Assari S.Unequal Gain of Equal Resources across Racial Groups. Int J Health Policy Manag, 2018, 7: 1-9.

10. Assari S, Bazargan M. Unequal Effects of Educational Attainment on Workplace Exposure to Second-Hand Smoke by Race and Ethnicity: Minorities' Diminished Returns in the National Health Interview Survey. J Med Res Innov. 2019;3(2):e000179.

11. Gee GC, Ford CL. Structural racism and health inequities: old issues, new directions. Du Bois Rev. 2011;8(1):115-132.

12. Williams DR, Mohammed SA. Racism and health I: pathways and scientific evidence. Am Behav Sci. 2013;57(8). doi:10.1177/0002764213487340

13. Xin Z, Yi Z, Tan HQ, Lin HX et al. Spillover effects of children's political status on elderly parents' health in China. Journal of epidemiology and community health, 2018, 72: 973-981.

14. Sun J, Lyu S. The effect of medical insurance on catastrophic health expenditure: evidence from China. Cost Eff Resour Alloc, 2020, 18: 10.

15. Cohen, J. (1988). Statistical power analysis for the behavioral sciences (2nd ed.). Hillsdale, NJ: Eribaum.

16. Lin H, Lin Y, Zheng Y, Liu Z, Chang C. Design, development and randomised controlled trial of a smartphone application,'QinTB', for smoking cessation in tuberculosis patients: study protocol. BMJ OPEN 2019;9:e031204.

17. Fichtenberg, CM. Effect of smoke-free workplaces on smoking behaviour: systematic review. BMJ, 2002, 325(7357):188188.

18. Brown TH, O'Rand AM, Adkins DE. Race-ethnicity and health trajectories: tests of three hypotheses across multiple groups and health outcomes. J Health Soc Behav. 2012;53(3):359-377.

19. Assari S, Thomas A, Caldwell CH, Mincy RB. Blacks' diminished health return of family structure and socioeconomic status; 15 years of follow-up of a national urban sample of youth. J Urban Health 2018; 95:21-35.

20. Assari S. High income protects whites but not African Americans against risk of depression. Healthcare (Basel) $2018 ; 6:$ E37.

\section{Tables}

Table 1. Descriptive statistics in the overall sample 


\begin{tabular}{|c|c|}
\hline Demographics & $n / \%$ \\
\hline \multicolumn{2}{|l|}{ Age } \\
\hline $16-29$ & $6228 \rrbracket 43.9 \rrbracket$ \\
\hline $30-39$ & $5932 \bigotimes 41.8 \rrbracket$ \\
\hline $40-49$ & 1794ه12.6ه \\
\hline 50 and above & $241 \otimes 1.7 \rrbracket$ \\
\hline Mean age (SD) & $31.60 \pm 7.27$ \\
\hline \multicolumn{2}{|l|}{ Gender } \\
\hline Male & $6408(45.1)$ \\
\hline Female & $7787(54.9)$ \\
\hline \multicolumn{2}{|l|}{ Ethnicity } \\
\hline Han & $13594 \rrbracket 95.8 \rrbracket$ \\
\hline Others & $601 \rrbracket 4.2 \rrbracket$ \\
\hline \multicolumn{2}{|l|}{ Marriage } \\
\hline Single & $5534 \rrbracket 39.0 \bigotimes$ \\
\hline Married & 8491囚59.8囚 \\
\hline Divorced or widowed & $170 \otimes 1.2 \rrbracket$ \\
\hline \multicolumn{2}{|l|}{ Education attainment } \\
\hline High school/lower & $2556(18.0)$ \\
\hline College / above & 11639(82.0) \\
\hline \multicolumn{2}{|c|}{ Secondhand smoke exposure } \\
\hline Never & $6429 ه 45.3 \rrbracket$ \\
\hline 1 to 3 days per week & $4423 \rrbracket 31.2 \rrbracket$ \\
\hline 4 to 6 days per week & $981 \rrbracket 6.9 \rrbracket$ \\
\hline Every day & $2362 \bigotimes 16.6 \rrbracket$ \\
\hline \multicolumn{2}{|l|}{ Smoking } \\
\hline Yes & $2955 \rrbracket 20.8 \rrbracket$ \\
\hline No & 11240ه79.2区 \\
\hline \multicolumn{2}{|c|}{ Awareness on smoking harm } \\
\hline Yes & $1779 \otimes 12.5 \rrbracket$ \\
\hline No & $12416 \rrbracket 87.5 \rrbracket$ \\
\hline \multicolumn{2}{|l|}{ Job position } \\
\hline Not administrative & $9458(66.6)$ \\
\hline Administrative & $4737(33.4)$ \\
\hline
\end{tabular}

Page 9/14 
14195

Table 2. Bivariate correlation in the overall sample

\begin{tabular}{|c|c|c|c|c|c|c|c|c|}
\hline Characteristics & 1 & 2 & 3 & 4 & 5 & 6 & 7 & 8 \\
\hline Heath education & 1.000 & $0.019 *$ & $0.020^{\star}$ & $0.099 * *$ & $-0.050 * \star$ & $0.112^{\star \star}$ & $0.139 \star \star$ & $0.118^{\star \star}$ \\
\hline Job position & & 1.000 & $0.121^{\star \star}$ & -0.002 & 0.009 & $0.052 * \star$ & $0.050 * *$ & $0.043^{\star \star}$ \\
\hline Education attainment & & & 1.000 & $0.072 * \star$ & -0.093 & $0.115^{\star \star}$ & $0.060 * *$ & $0.018^{\star}$ \\
\hline Smoking harm knowledge & & & & 1.000 & 0.001 & $0.031 * \star$ & 0.009 & $0.106^{\star \star}$ \\
\hline Second-hand smoke exposure & & & & & 1.000 & -0.106 ** & $-0.085^{\star \star}$ & $-0.050 * \star$ \\
\hline $\begin{array}{l}\text { Believe Working in a healthy } \\
\text { environment }\end{array}$ & & & & & & 1.000 & $0.443^{\star \star}$ & $0.078^{\star \star}$ \\
\hline $\begin{array}{l}\text { Believe workplace policy protects } \\
\text { health of employees }\end{array}$ & & & & & & & 1.000 & $0.082^{\star \star}$ \\
\hline Search health information & & & & & & & & 1.000 \\
\hline
\end{tabular}

Note: ${ }^{*} \mathrm{p}<0.05,{ }^{*} \mathrm{p}<0.01$, Spearman correlation test.

Table 3. Summary of logistic regression models on workplace SHS exposure and smoking harm awareness 


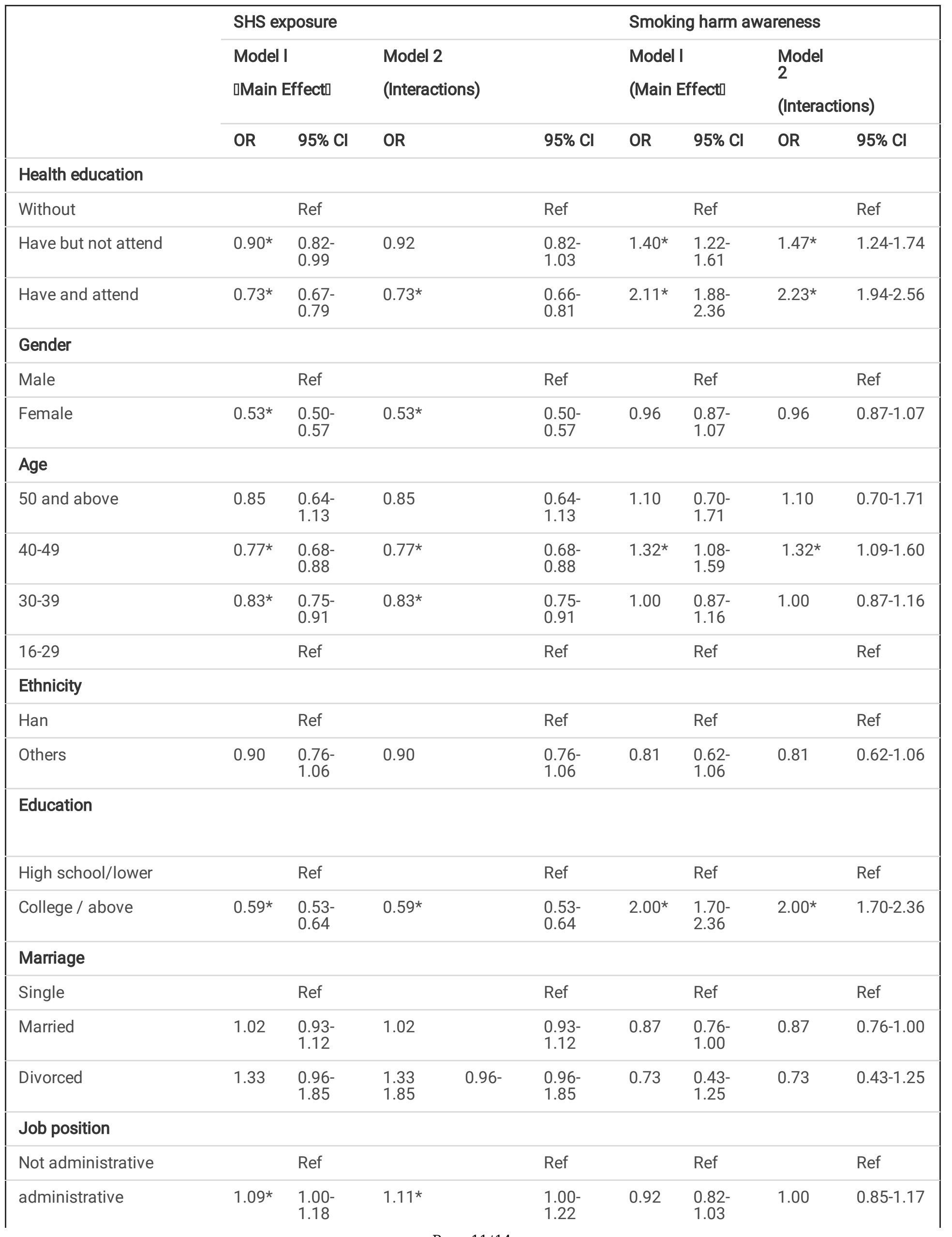

Page 11/14 


\section{Health training $\times$ Job}

position

\begin{tabular}{|c|c|c|c|c|}
\hline Without & & Ref & & Ref \\
\hline Have but not attend & 0.93 & $\begin{array}{l}0.76- \\
1.14\end{array}$ & 0.86 & $0.63-1.16$ \\
\hline Have and attend & 0.97 & $\begin{array}{l}0.83- \\
1.17\end{array}$ & 0.85 & $0.67-1.08$ \\
\hline
\end{tabular}

Note: ${ }^{*} p<0.05$

Model 1 only entered the main effects of health education, job position and covariates.

Model 2 was also added interaction terms between health education and job position.

Table 4. Summary of logistic regression models on perceived workplace environment and health information-seeking behavior 
Believe working in a

healthy environment

$\begin{array}{ll}\text { Model I } & \text { Model } \\ \text { [Main Effect] } & 2\end{array}$

(Interactions)
Believe workplace policy

protects health

$\begin{array}{ll}\text { Model I } & \text { Model } \\ \text { (Main Effectl } & 2 \\ & \text { (Interactic }\end{array}$
Health information-seeking behavior

\section{$\begin{array}{lllllllllllll}\text { OR } & \begin{array}{lllll}95 \% \\ \mathrm{Cl}\end{array} & \text { OR } & 95 \% \mathrm{Cl} & \text { OR } & \begin{array}{l}95 \% \\ \mathrm{Cl}\end{array} & \text { OR } & 95 \% \mathrm{Cl} & \text { OR } & \begin{array}{l}95 \% \\ \mathrm{Cl}\end{array} & \text { OR } & \begin{array}{l}95 \% \\ \mathrm{Cl}\end{array}\end{array}$}

\section{Health}

education

\begin{tabular}{|c|c|c|c|c|c|c|c|c|c|c|c|c|}
\hline Without & & Ref & & Ref & & Ref & & Ref & & Ref & & Ref \\
\hline $\begin{array}{l}\text { Have but not } \\
\text { attend }\end{array}$ & $1.42^{\star}$ & $\begin{array}{l}1.27- \\
1.59\end{array}$ & $1.28^{*}$ & $\begin{array}{l}1.12- \\
1.45\end{array}$ & $1.44^{*}$ & $\begin{array}{l}1.29- \\
1.62\end{array}$ & $1.36^{\star}$ & $\begin{array}{l}1.19- \\
1.55\end{array}$ & $1.15^{\star}$ & $\begin{array}{l}1.04- \\
1.28\end{array}$ & 1.04 & $\begin{array}{l}0.91- \\
1.18\end{array}$ \\
\hline $\begin{array}{l}\text { Have and } \\
\text { attend }\end{array}$ & $2.04^{\star}$ & $\begin{array}{l}1.84- \\
2.26\end{array}$ & $1.84^{\star}$ & $\begin{array}{l}1.63- \\
2.08\end{array}$ & $2.87 *$ & $\begin{array}{l}2.55- \\
3.23\end{array}$ & $2.60 *$ & $\begin{array}{l}2.27- \\
2.99\end{array}$ & $2.17 *$ & $\begin{array}{l}1.99- \\
2.36\end{array}$ & $2.07 *$ & $\begin{array}{l}1.86- \\
2.30\end{array}$ \\
\hline
\end{tabular}

\section{Gender}

\begin{tabular}{|c|c|c|c|c|c|c|c|c|c|c|c|c|}
\hline Male & & Ref & & Ref & & Ref & & Ref & & Ref & & Ref \\
\hline Female & $1.31^{\star}$ & $\begin{array}{l}1.21- \\
1.41\end{array}$ & $1.31^{*}$ & $\begin{array}{l}1.21- \\
1.42\end{array}$ & $1.18^{*}$ & $\begin{array}{l}1.09- \\
1.28\end{array}$ & $1.18^{*}$ & $\begin{array}{l}1.09- \\
1.28\end{array}$ & $1.29 *$ & $\begin{array}{l}1.20- \\
1.39\end{array}$ & $1.29 *$ & $\begin{array}{l}1.20- \\
1.39\end{array}$ \\
\hline
\end{tabular}

\section{Age}

\begin{tabular}{|c|c|c|c|c|c|c|c|c|c|c|c|c|}
\hline 50 and above & 1.23 & $\begin{array}{l}0.90- \\
1.67\end{array}$ & 1.23 & $\begin{array}{l}0.91- \\
1.67\end{array}$ & 1.32 & $\begin{array}{l}0.95- \\
1.85\end{array}$ & 1.32 & $\begin{array}{l}0.95- \\
1.85\end{array}$ & $1.78^{*}$ & $\begin{array}{l}1.34- \\
2.37\end{array}$ & $1.79 *$ & $\begin{array}{l}1.34- \\
2.38\end{array}$ \\
\hline $40-49$ & $1.31^{*}$ & $\begin{array}{l}1.13- \\
1.52\end{array}$ & $1.31 *$ & $\begin{array}{l}1.13- \\
1.52\end{array}$ & $1.30 *$ & $\begin{array}{l}1.10- \\
1.52\end{array}$ & $1.29 *$ & $\begin{array}{l}1.10- \\
1.51\end{array}$ & $1.60 *$ & $\begin{array}{l}1.39- \\
1.83\end{array}$ & $1.59 *$ & $\begin{array}{l}1.39- \\
1.83\end{array}$ \\
\hline $30-39$ & $1.14^{\star}$ & $\begin{array}{l}1.03- \\
1.28\end{array}$ & $1.14^{\star}$ & $\begin{array}{l}1.03- \\
1.27\end{array}$ & $1.17^{*}$ & $\begin{array}{l}1.05- \\
1.31\end{array}$ & $1.17 *$ & $\begin{array}{l}1.05- \\
1.31\end{array}$ & $1.15^{\star}$ & $\begin{array}{l}1.04- \\
1.27\end{array}$ & $1.14^{\star}$ & $\begin{array}{l}1.03- \\
1.26\end{array}$ \\
\hline $16-29$ & & Ref & & Ref & & Ref & & Ref & & Ref & & Ref \\
\hline
\end{tabular}

\section{Ethnicity}

\begin{tabular}{|c|c|c|c|c|c|c|c|c|c|c|c|c|}
\hline Han & & Ref & & Ref & & Ref & & Ref & & Ref & & Ref \\
\hline Others & 1.03 & $\begin{array}{l}0.85- \\
1.26\end{array}$ & 1.03 & $\begin{array}{l}0.85- \\
1.25\end{array}$ & 0.98 & $\begin{array}{l}0.81- \\
1.20\end{array}$ & 0.989 & $\begin{array}{l}0.81- \\
1.21\end{array}$ & 0.97 & $\begin{array}{l}0.81- \\
1.16\end{array}$ & 0.97 & $\begin{array}{l}0.80- \\
1.16\end{array}$ \\
\hline
\end{tabular}

\section{Education}

\begin{tabular}{|c|c|c|c|c|c|c|c|c|c|c|c|c|}
\hline $\begin{array}{l}\text { High } \\
\text { school/lower }\end{array}$ & & Ref & & Ref & & Ref & & Ref & & Ref & & Ref \\
\hline $\begin{array}{l}\text { College / } \\
\text { above }\end{array}$ & $1.89 *$ & $\begin{array}{l}1.71- \\
2.09\end{array}$ & $1.86^{\star}$ & $\begin{array}{l}1.67- \\
2.05\end{array}$ & $1.44^{\star}$ & $\begin{array}{l}1.29- \\
1.60\end{array}$ & $1.44^{*}$ & $\begin{array}{l}1.29- \\
1.60\end{array}$ & $1.19 *$ & $\begin{array}{l}1.07- \\
1.31\end{array}$ & $1.19 *$ & $\begin{array}{l}1.07- \\
1.31\end{array}$ \\
\hline \multicolumn{13}{|l|}{ Marriage } \\
\hline Single & & Ref & & Ref & & Ref & & Ref & & Ref & & Ref \\
\hline Married & $0.89 *$ & $\begin{array}{l}0.80- \\
0.99\end{array}$ & $0.89 *$ & $\begin{array}{l}0.80- \\
0.99\end{array}$ & 0.96 & $\begin{array}{l}0.86- \\
1.07\end{array}$ & 0.96 & $\begin{array}{l}0.86- \\
1.07\end{array}$ & 1.00 & $\begin{array}{l}0.91- \\
1.11\end{array}$ & 1.00 & $\begin{array}{l}0.91- \\
1.11\end{array}$ \\
\hline Divorced & $0.67 *$ & $0.47-$ & $0.67 *$ & $0.47-$ & 0.88 & $0.60-$ & 0.88 & $0.60-$ & 1.07 & $0.76-$ & 1.07 & $0.76-$ \\
\hline
\end{tabular}



0.96
0.96
1.28
1.28
1.50
1.50

\section{Job position}

\begin{tabular}{|c|c|c|c|c|c|c|c|c|c|c|c|c|}
\hline $\begin{array}{l}\text { Not } \\
\text { administrative }\end{array}$ & & Ref & & Ref & & Ref & & Ref & & Ref & & Ref \\
\hline administrative & $1.22 *$ & $\begin{array}{l}1.11- \\
1.34\end{array}$ & 1.09 & $\begin{array}{l}0.97- \\
1.21\end{array}$ & $1.20 *$ & $\begin{array}{l}1.09- \\
1.32\end{array}$ & 1.10 & $\begin{array}{l}0.99- \\
1.23\end{array}$ & $1.12^{\star}$ & $\begin{array}{l}1.02- \\
1.20\end{array}$ & 1.01 & $\begin{array}{l}0.91- \\
1.13\end{array}$ \\
\hline
\end{tabular}

\section{Health \\ training $\times$ Job \\ position}

\begin{tabular}{|c|c|c|c|c|c|c|}
\hline Without & & Ref & & Ref & Ref & Ref \\
\hline $\begin{array}{l}\text { Have but not } \\
\text { attend }\end{array}$ & $1.46^{\star}$ & $\begin{array}{l}1.14- \\
1.87\end{array}$ & 1.24 & $\begin{array}{l}0.96- \\
1.59\end{array}$ & $1.36 *$ & $\begin{array}{l}1.09 \\
1.68\end{array}$ \\
\hline $\begin{array}{l}\text { Have and } \\
\text { attend }\end{array}$ & $1.41^{*}$ & $\begin{array}{l}1.12- \\
1.76\end{array}$ & $1.39 *$ & $\begin{array}{l}1.07- \\
1.81\end{array}$ & 1.15 & $\begin{array}{l}0.96 \\
1.37\end{array}$ \\
\hline
\end{tabular}

Note: ${ }^{*} p<0.05$

Model 1 only entered the main effects of health education, job position and covariates.

Model 2 was also added interaction terms between health education and job position

\section{Figures}

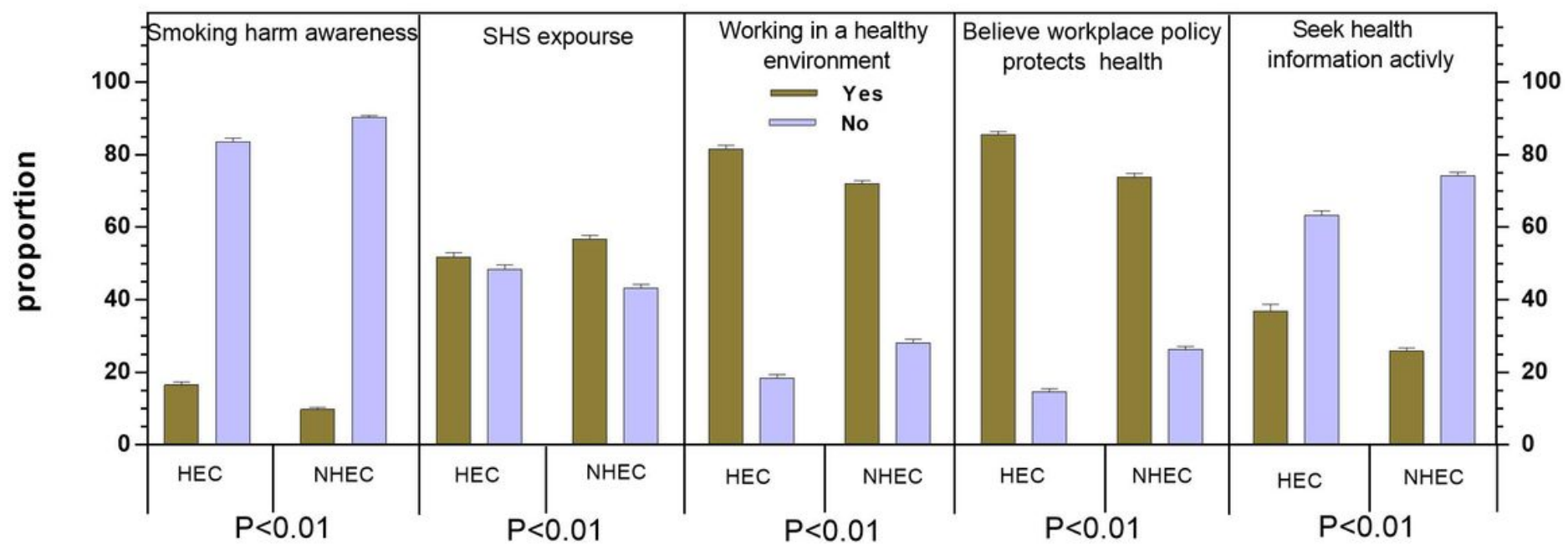

HEC:emplyees working in companies have tobacco related health education NHEC:emplyees working in companies without tobacco related health education

\section{Figure 1}

Proportion of employees by health related characteristics. 